Maria Celi Chaves Vasconcelos

\begin{abstract}
A CASA E OS SEUS MESTRES:
A EDUCAÇÃO DOMÉSTICA COMO UMA PRÁTICA DAS ELITES NO BRASIL DE OITOCENTOS

Tese de Doutorado

Tese apresentada ao Programa de Pós-graduação em Educação do Departamento de Educação da PUC-Rio como parte dos requisitos parciais para obtenção do título de Doutor em Educação.
\end{abstract}

Orientador: Ana Waleska Pollo Campos Mendonça

Volume I

Rio de Janeiro

Fevereiro de 2004 
Maria Celi Chaves Vasconcelos

\title{
A CASA E OS SEUS MESTRES: \\ A EDUCAÇÃO DOMÉSTICA COMO UMA PRÁTICA DAS ELITES NO BRASIL DE OITOCENTOS
}

Tese apresentada ao como requisito parcial para obtenção do grau de Doutor pelo Programa de Pós-graduação em Educação do Departamento de Educação do Centro de Teologia e Ciências Humanas da PUC-Rio. Aprovada pela Comissão Examinadora abaixo assinada.

\author{
Prof. Ana Waleska Pollo Campos Mendonça \\ Orientador \\ Departamento de Educação - PUC-Rio \\ Prof. Isabel Alice O. M. Lelis \\ Departamento de Educação - PUC-Rio \\ Prof. Alicia Bonamino \\ Departamento de Educação - PUC-Rio \\ Prof. Maria de Lourdes de A. Fávero \\ UCP \\ Prof. Ana Maria B. de Mello Magaldi \\ Departamento de História - PUC-Rio
}

Prof. Jürgen Heye

Coordenador Setorial do Centro de Teologia e

Ciências Humanas

Rio de Janeiro, 03 de fevereiro de 2004 
Todos os direitos reservados. É proibida a reprodução total ou parcial do trabalho sem a autorização da universidade, da autora e da orientadora.

\section{Maria Celi Chaves Vasconcelos}

Maria Celi Chaves Vasconcelos graduou-se em História, em 1984, pela Faculdade de Filosofia, Ciências e Letras - FIC/RS e graduou-se em Pedagogia, em 1994, pela Universidade Federal Fluminense - UFF. Pós-graduada em Educação Ambiental pela UFF, em 1996. Obteve o título de pós-graduada em Educação Ambiental pela UFF, em 1996. Obteve o título de Mestre em Educação na Universidade Federal do Rio de Janeiro - UFRJ, em 1999. Trabalhou como professora de História no ensino fundamental e no ensino médio, nas redes públicas do Município do Rio de Janeiro e do Estado do Rio de Janeiro. Foi supervisora pedagógica assistente da Faculdade de Educação da Baixada Fluminense - UERJ.

Ficha Catalográfica

Vasconcelos, Maria Celi Chaves

A casa e os seus mestres: a educação doméstica como prática das elites no Brasil de oitocentos / Maria Celi Chaves Vasconcelos; orientadora: Ana Waleska Pollo Campos Mendonça. - Rio de Janeiro: PUC, Departamento de Educação, 2004.

2 v. ; $336 f ; 30 \mathrm{~cm}$

Tese (doutorado) - Pontifícia Universidade Católica do Rio de Janeiro, Departamento de Educação.

Inclui referências bibliográficas.

1. Educação - Teses. 2. Educação doméstica. 3. Professores particulares. 4. Preceptores. 5. Educação feminina. 6. Brasil Oitocentista. I. Mendonça, Ana Waleska Pollo. II. Pontifícia Universidade Católica do Rio de Janeiro. Departamento de Educação. IV. Título. 
Para Júlio, Fernanda, Fabrício e Lucinha, pelo apoio, dedicação e paciência em tantas ausências. 


\section{Agradecimentos}

Ao professor Rogério Fernandes, pela generosidade, atenção e aconselhamentos com que me distinguiu ao longo da realização deste estudo.

À professora Ana Waleska Pollo Campos Mendonça, pelo acompanhamento cuidadoso, disponibilidade e sabedoria na orientação deste estudo.

À minha professora Isabel Lelis e ao professor Ilmar Mattos, pelas importantes contribuições na realização deste trabalho.

Aos meus pais Hugo e Eudóxia, pelo apoio, atenção e carinho constantes.

A Edgard e Maria Zélia de Brito Chaves, meus mestres da Casa, pela dedicação na revisão deste estudo.

À professora Lia Faria pelo apoio, confiança e por esse jeito contagiante "de achar que a vida pode ser maravilhosa".

À Vera Lúcia Menezes e Cláudio Xavier, respectivamente, responsáveis pela Divisão de Microrreprodução e setor de digitalização da Fundação Biblioteca Nacional, pelo auxílio concedido, sem o qual este trabalho não poderia ter sido realizado.

Ao meu Chefe de Departamento Paulo Mainhard, pelo apoio e lealdade nos momentos mais difíceis.

Aos meus amigos Helenice, Gelson, Merçon, Cléia, Maria, Maria Adélia, Marisol, Ana Lúcia, Luzia, Yolanda, Francisca, Edilamar, Fátima, Lourdes Therezinha, Tânia, Zezé, pelo carinho demonstrado.

Aos meus alunos, pelos ensinamentos e estímulo.

A todos os amigos e familiares que, de alguma forma, estiveram presentes nesta caminhada. 


\section{Resumo}

Vasconcelos, Maria Celi Chaves; Mendonça, Ana Waleska Pollo Campos. A Casa e os seus mestres: A educação doméstica como uma prática das elites no Brasil de Oitocentos. Rio de Janeiro, 2004. 336p. Tese de Doutorado - Departamento de Educação, Pontifícia Universidade Católica do Rio de Janeiro.

A educação doméstica foi uma significativa prática de educação realizada nas Casas do Brasil de Oitocentos, que, em determinados momentos, consistiu na forma majoritária de ensinamentos dados a crianças e jovens, naquele tempo e contexto. Realizada pelos mestres, que se caracterizavam como professores particulares, preceptores, ou mesmo por familiares e padres, essa modalidade foi uma prática constante de educação durante todo o Brasil Imperial, tendo sua origem na educação de príncipes e nobres e sendo marcada pela influência européia. A tese propõe-se a estudar as características dessa prática e das circunstâncias em que ocorria na Casa, bem como, as relações que se estabeleciam entre ela, os colégios particulares e a escola estatal emergente, em um cotidiano em que conviviam essas diferentes modalidades de educação, concebidas como formas reconhecidas de educar meninos e meninas em Oitocentos. A pesquisa está baseada em diversos tipos de fontes documentais, principalmente em periódicos da época, que, explicitamente, apresentam como se configuravam as práticas de educação realizadas na Casa e como se inscrevem nesse período os mestres, agentes e responsáveis pela educação das crianças de elite no Brasil Oitocentista.

\section{Palavras-chave}

Educação doméstica; Casa; Estado; mestres; professores particulares; preceptores; educação e instrução; elites; infância; educação feminina; Brasil Oitocentista. 


\section{Abstract}

Vasconcelos, Maria Celi Chaves; Mendonça, Ana Waleska Pollo Campos (Advisor). The Home and its Masters: Education at home as a practice of the elites in Brazil in the 19th Century. Rio de Janeiro, 2004. 336p. Tese de Doutorado - Departamento de Educação, Pontifícia Universidade Católica do Rio de Janeiro.

Education at home was a significant educational practice held at the Brazilian Homes in the 18th Century, which, in some moments, represented the largest share of education imparted to the young and to the children, at that time and situation. Held over by masters, who assumed the position of teachers and tutors private, or even by members of the family or priests, it was a constant practice in education all over the Imperial period in Brazil, having as its model the education imparted to princes and the nobility, and as its main feature the European influence. The thesis proposes studying the characteristics of this practice and of the circumstances in which it happened at the House, as well as the relationships established among it, the private schools and the emerging state schools, in a daily life involving the different means of education conceived as methods to educate boys and girls in the $18^{\text {th }}$ Century. The research is based on several kinds of documental sources, mainly from periodicals of the time, which show clearly how the educational practices held at Home were planned and how the masters, the agents and the ones in charge of the education of the children of the elite in Brazil of the Eighteen Hundreds were inscribed in the period.

\section{Keywords}

Education at home; Home; State; masters; teachers and tutors private; education and instruction; elites; infancy; education feminine; Brazil of the Eighteen. 


\section{SUMÁRIO}

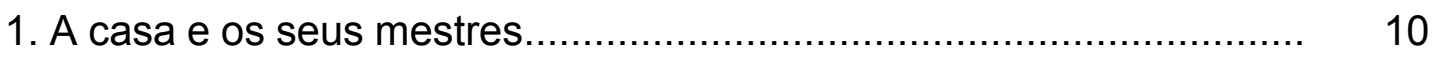

1.1. O estudo da Educação Doméstica ............................................. 10

1.2. Caminhos percorridos e fontes utilizadas ................................... 15

2. Educação Doméstica: uma prática educacional das elites no Brasil de Oitocentos

2.1. A Educação Doméstica: registros de uma prática das elites

2.2. Os Mestres das Casas: caracterização e habilitação dos agentes

2.3. As circunstâncias em que ocorria a Educação Doméstica: o lugar social ocupado, os conhecimentos ensinados e os métodos utilizados na educação das Casas

2.4. A educação Doméstica na literatura brasileira Oitocentista

3. O Contexto da influência européia na Educação Doméstica do Brasil de Oitocentos

3.1. Diferentes contextos: Portugal, França e Inglaterra

3.2. A propagação da literatura para a Educação Doméstica

4. Infância e educação nas Casas Oitocentistas: a mãe e mestra ........ 217

4.1. Infância e educação de meninos e meninas nas Casas ................ 218

4.2. As mães de família: a importância da educação feminina para o ensinamento dos filhos

5. A relação Casa e Estado na educação Oitocentista

5.1. O Governo da Casa e o Governo do Estado no debate educacional de Oitocentos

5.2. Educação, instrução e obrigatoriedade do ensino: a quem cabe a educação?

6. Educação doméstica: a constatação de uma prática e a sua significação em Oitocentos

7. Referências bibliográficas

8. Anexos 


\section{Lista de figuras}

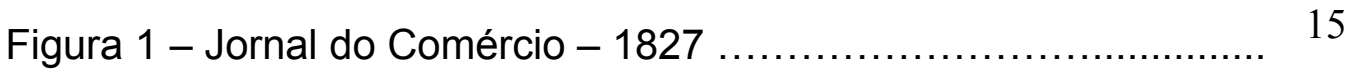

Figura 2 - Diário de Lembraças da Viscondessa do Arcozelo ........... 15

Figura 3 - Fotografia de Mulher (século XIX) ........................... 24

Figura 4 - Colégio de Meninas ......................................... 24

Figura 5 - Jean-Baptiste Debret - Une dame d' une fortune ordinaire dans son intérieur au milieu de ses habitudes journalières, 1823

Figura 6 - O Recreio: Jornal das Famílias, Lisboa, Julho de 1842 ....

Figura 7 - O Recreio: Jornal das Famílias, Lisboa, setembro de 1836

Figura 8 - Literatura para a educação doméstica

Figura 9 - Literatura para a educação doméstica

Figura 10 - Literatura para a educação doméstica

Figura 11 - Literatura para a educação doméstica

Figura 12 - Menino com a sua ama

Figura 13 -Tela da Princesa Isabel na infância

Figura 14 - Jornal A Mãi de Família

Figura 15 - Jornal A Mãi de Família

Figura 16 - Giuseppe Gambarini, O Inverno (1721-c. 1727). Bolonha, Pinacoteca Nazionale

Figura 17 - Georges de la Tour, O recém-nascido, Rennes, Musée dês Beaux-Arts 